\title{
Cyclic Timetable Scheduling Problem on High-speed Railway Line
}

\author{
Wen Xu1 , Yuyan Tan, Bishal Sharma', Ziyulong Wang ${ }^{1}$ \\ ${ }^{1}$ Department of Transportation Management Engineering, School of Traffic and Transportation, Beijing Jiaotong University, \\ No. 3 Shangyuancun, Haidian District, 100044 Beijing, China \\ * Corresponding author, e-mail: yytan@bjtu.edu.cn
}

Received: 28 March 2018, Accepted: 24 June 2018, Published online: 15 April 2019

\begin{abstract}
Due to several obvious advantages both in transport marketing and train operation planning, the cyclic timetable has already applied in many high-speed railway (HSR) countries. In order to adopt the cyclic timetable in China's HSR system, a Mixed Integer Programmer (MIP) model is proposed in this paper involving many general constraints, such as running time, dwell time, headway, and connection constraints. In addition, the real-world overtaking rule that concerning a train with higher priority will not be overtaken by a slower one is incorporated into the cyclic timetable optimization model. An approach based on fixed departure is proposed to get a cyclic timetable with minimum total journey time within a reasonable time. From numerical investigations using data from Guangzhou-Zhuhai HSR line in China, the proposed model and associated approach are tested and shown to be effective.
\end{abstract}

Keywords

high-speed railway, cyclic train timetable, overtaking rule, MIP model, fixed departure order

\section{Introduction}

As an important mode of public transportation, railway transportation serves as a backbone transportation system in the comprehensive transport network in many countries. Traditionally, the overall railway planning problem could be summarized by the following steps, as shown in Fig. 1, and these six sub-tasks are usually solved sequentially.

Step1: Passenger Flow Forecasting. The OriginsDestinations (ODs) matrix of passenger flow is determined, which specifies the estimated number of passengers on a day between each pair of stations.

Step 2: Train Line Planning. Based on the forecasts, the train lines, which include the information of connecting stations, train types, numbers of trains and stopping plan, are determined.

Step 3: Timetabling. Train timetable is scheduled based on the given the train line plan to indicate the departure, arrival or passing time for each train at stations.

Step 4: Vehicle Scheduling. The vehicle is arranged based on the timetable and the rolling stock maintenance schedule in accordance with the scheduled time and the rolling stock maintenance rules.

Step 5: Crew Scheduling. The crew plan is scheduled to determine when and where the crew attends the train and which train to serve, based on the given train timetable and crew management regulations.

Step 6: Re-scheduling. When the interruptions or disturbances occur, the trains can be rescheduled and the locomotive plan should be rescheduled to suit the actual situation.

Timetable is an important technical document for passenger and railway transport production, and also the basis for organizing train operation. Therefore, timetabling is the key part of the process of railway train operation, and in this paper, our study focus on the timetable scheduling problem.

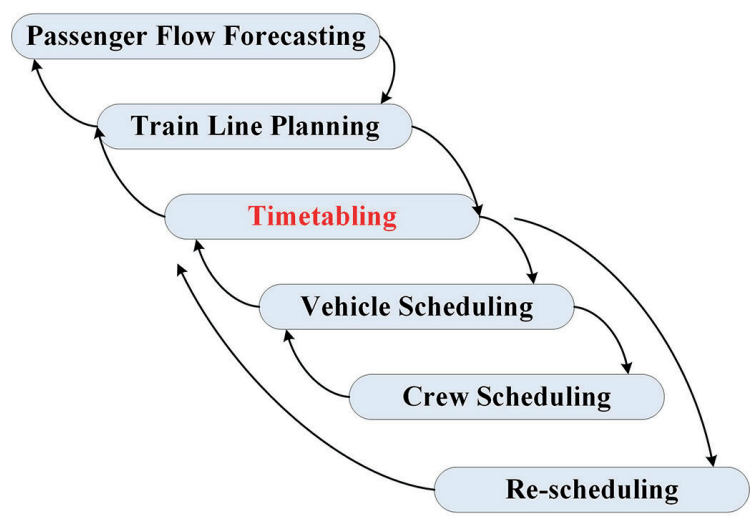

Fig. 1 The process of railway train operation 
There are two types of timetable applied in the railway transportation system in the world, including cyclic timetable and non-cyclic timetable. In a non-cyclic timetable, there is usually no special rule for train operation. That is, each train has a schedule that is independent of other trains, which makes the non-cyclic timetable more flexible. On the other hand, a cyclic timetable is always recognized as passenger-oriented, since the repeated departure and arrival time every cycle time offer accessibility and regularity for passengers, and the length of cycle time is usually set every one or two hours. The process of the cyclic timetabling is shown as in Fig. 2, and the steps are listed as follows.

Step 1: One Cycle Period Timetable. The train diagram in peak hours can be obtained by solving the model based on the train line plan in peak-hour time.

Step 2: Full-day Timetable. After removing or adjusting the trains running during the maintenance time, the full-day timetable can be obtained by copying the cyclic unit timetable for all the relevant hours of the day.

Step 3: Generic Cyclic Timetable. By cancelling a number of trains during off-peak hours appropriately according to the passenger flow, we can get the generic cyclic timetable.

Cyclic timetable has several obvious advantages both in transport marketing and train operation planning. Firstly, from the view of customers, it is no need for them to memorize the complex timetables since the train and interchanging connections would be operated regularly with respect to a cycle time. Secondly, from a planning point of view, planning would become much simpler based on one cycle time due to the fact that the whole day cyclic timetable could be realized by copying one cycle for all relevant hours of a day. Therefore, the cyclic timetable is widely used in foreign high-speed railway system.

In recent years, the cyclic timetabling problem is usually formulated based on the Periodic Event Scheduling Problem (PESP), which is introduced by Serafini and

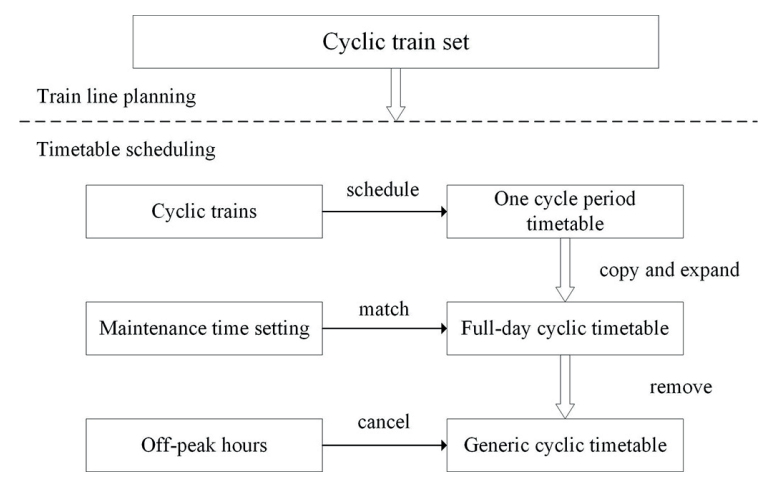

Fig. 2 The process of cyclic timetable planning
Ukovich (1989). A PESP based model for the cyclic railway timetabling problem for NS is presented by Peeters (2003). With the aim to minimize the length of the dispatching cycle, a mixed integer linear program is proposed by the Heydar et al. (2013). Moreover, Robenek et al. (2017) developed a new train timetable that would consider not only the regularity of cyclic timetable but also the flexibility of the non-cyclic one. Scheduling train timetables with the objective of tardiness minimization can be seen in Oliveira and Smith (2001), Mackenzie (2000) and Mu and Dessouky (2011). Furthermore, Kroon et al. (2013) demonstrated how to model the rolling stock and passenger connections in a cyclic timetable based on PESP.

In addition, some algorithms for cyclic timetabling based on the PESP have been studied. A first Mixed Integer Programming (MIP) formulation based on EventActivity GraphModel is given in Schöbel (2001) and further developed in Schöbel (2007) and Schachtebeck (2010). Zimmermann and Lindner (2000) solved train timetabling and railway line planning integrated problem using PESP formulation. Peeters (2003) illustrated mathematical models and solutions for constructing high-quality cyclic train timetables. Arbitrary disturbances can be coped in the timetable designed by Kroon et al. (2013). When a disturbance occurred in an $n$-tracked network, Törnquist and Persson (2007) gave an optimization method with scheduling railway traffic. Xie and Nie (2009) proposed an optimization model based on the fixed train order. Su et al. (2013) put forward an integer optimization model, which considered both the timetable and the velocity curve.

Our study varies from the previous ones from two aspects. Firstly, train overtaking rule is considered in order to ensure that trains with lower priority cannot overtake higher ones. Secondly, an approach based on a fixed departure order at original station is presented to get a cyclic timetable within a reasonable time.

The structure of the manuscript is as follows. Firstly, we present the basic mathematical model for the cyclic railway timetabling problem, and then an approach based on fixed order is proposed in Section 2. In Section 3, numerical investigation and case study demonstrate the quality of solutions that are obtained from proposed approach. In Section 4 the outcomes and the significance of the paper are summarized and the future research directions are given.

\section{Mathematical Model}

This section formulates a general mixed integer program (MIP) model for cyclic railway timetabling problem. 
This model is described based on the event-activity graph, and then an approach based on fixed order is proposed to get the cyclic timetable within a reasonable time.

\subsection{Railway network input}

A directed graph $G=(V, E)$ represents an event-activity graph with events represented by nodes $V$ and activity represented by directed edges $E$ which is firstly used by Schöbel (2001) in timetabling, as shown in Fig. 3. In the event-activity graph, an activity which connects two events represents a precedence constraint between those events. For a single activity, an upper and/or lower bound is set on its duration.

The set $V$ of events consists of all arrival events and departure events, i.e. $V=V_{\text {arr }} \cup V_{\text {dep }}$, $V_{\text {arr }}=\{(t, s$, arrival $):$ train $t$ arrives at station $s\}$ $V_{\text {dep }}=\{(t, s$, departure $):$ train $t$ departs from station $s\}$.

The events of set $V$ are linked by directed edge set $E$, which are called activities and consists:

- Trip activities: $E_{\text {trip }} \subset V_{\text {dep }} \times V_{\text {arr }}$ model driving of a train between two consecutive stations.

- Dwell activates: $E_{\text {dwell }} \subset V_{\text {arr }} \times V_{\text {dep }}$ model the stopping of a train at a station.

- Changing activities: $E_{\text {change }} \subset V_{\text {arr }} \times V_{\text {dep }}$ model a transfer connection from one station to another.

- Headway activities: $E_{\text {headway }} \subset V_{\text {dep }} \times V_{\text {dep }} \times V_{\text {arr }} \times V_{\text {arr }}$ model the security headway between two consecutive departures and arrivals at the same station.

\subsection{Decision Variables and Parameters}

The decision variables and parameters used in the mathematical model are listed in Tables 1 and 2, respectively. The unit of all time-related variables and parameters is one minute.

\subsection{General mathematical model for cyclic timetabling}

Let $x_{i}$ be the time slot of event $i \in V$ happens, the general mathematical model for cyclic timetabling are presented by Eqs. (1)-(6):

Minimize $F\left(x_{i}\right)$.

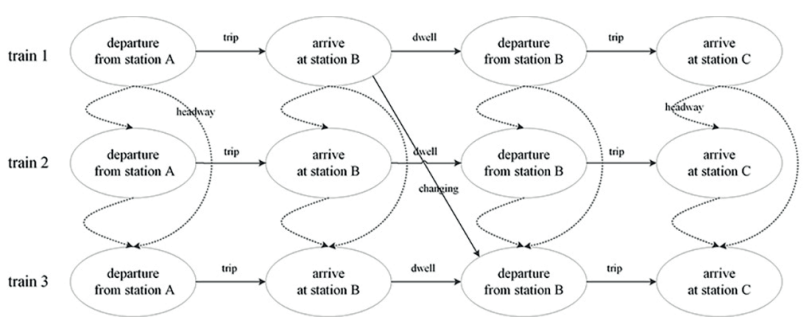

Fig. 3 The event-activity network for railway timetabling
Table 1 Decision variables used in mathematical model

\begin{tabular}{|c|c|}
\hline Symbol & Description \\
\hline$a_{t, s}$ & $\begin{array}{l}\text { The arrival time of train } t \text { at station } s \text {, } \\
0 \leq a_{t, s} \leq T-1,0 \leq t \leq n, 0 \leq s \leq m\end{array}$ \\
\hline$d_{t, s}$ & $\begin{array}{l}\text { The departure time of train } t \text { at station } s \text {, } \\
0 \leq d_{t, s} \leq T-1,0 \leq t \leq n, 0 \leq s \leq m \text {, }\end{array}$ \\
\hline$k_{t, s}=\left\{\begin{array}{l}0 \\
1\end{array}\right.$ & $\begin{array}{l}\text { If all the variables } a_{t, s} \text { and } d_{t, s} \text { of a certain train are at the } \\
\text { same time unit } \\
\text { Otherwise (binary, guarantee the constraints are positive) }\end{array}$ \\
\hline$k_{t, s}^{\prime}=\left\{\begin{array}{l}0 \\
1\end{array}\right.$ & $\begin{array}{l}\text { If all the variables } a_{t, s} \text { and } d_{t, s} \text { about two successive trains } \\
t \text { and } t+1 \text { or the trains } t \text { and } t^{\prime} \text { are at the same time unit } \\
\text { Otherwise }\end{array}$ \\
\hline$o_{t, s}=\left\{\begin{array}{l}0 \\
1\end{array}\right.$ & $\begin{array}{l}\text { If the train } t \text { travels before } t+1 \text { on the segment }[s, s+1] \\
\text { Otherwise }\end{array}$ \\
\hline Symbol & Description \\
\hline$r_{t, s}^{\min }$ & $\begin{array}{l}\text { Minimum travel time for train } t \text { in section }[s, s+1] \\
0 \leq s \leq m-1\end{array}$ \\
\hline$r_{t, s}^{\max }$ & $\begin{array}{l}\text { Maximum travel time for train } t \text { in section }[s, s+1] \\
0 \leq s \leq m-1\end{array}$ \\
\hline$d w_{t, s}^{\min }$ & Minimum dwell time for train $t$ at station $s, d w_{t, s}^{\min } \in N$ \\
\hline$d w_{t, s}^{\max }$ & Maximum dwell time for train $t$ at station $s, d w_{t, s}^{\max } \in N$ \\
\hline$h d_{s}$ & $\begin{array}{l}\text { The departure headway of consecutive trains at the } \\
\text { station } s, h d_{s} \in N\end{array}$ \\
\hline$h a_{s}$ & $\begin{array}{l}\text { The arrival headway of consecutive trains at the station } s \text {, } \\
h a_{s} \in N\end{array}$ \\
\hline$c_{t, s}^{\min }$ & $\begin{array}{l}\text { Minimum connection time for two trains } t \text { and } t^{\prime} \text { at the } \\
\text { station } s, c_{t, s}^{\min } \in N\end{array}$ \\
\hline$c_{t, s}^{\max }$ & $\begin{array}{l}\text { Maximum connection time for two trains } t \text { and } t^{\prime} \text { at the } \\
\text { station } s, c_{t, s}^{\max } \in N\end{array}$ \\
\hline$M$ & An infinite integer $(\infty)$ \\
\hline$T$ & Cycle length of timetable \\
\hline
\end{tabular}

Subject to:

Running time on segment:

$$
\begin{aligned}
x_{j}-x_{i} & \in\left[r_{e}^{\min }, r_{e}^{\max }\right]_{T} \\
\forall e & =(i, j) \in E_{\text {trip }} .
\end{aligned}
$$

Dwell time at station:

$$
\begin{aligned}
x_{j}-x_{i} & \in\left[\text { dwell }_{e}^{\min }, \text { dwell }_{e}^{\max }\right]_{T} \\
\forall e & =(i, j) \in E_{\text {dwell }} .
\end{aligned}
$$

Minimum headway

$$
\begin{aligned}
x_{j}-x_{i} & \in\left[h d_{s}, T-h d_{s}\right]_{T} \\
\forall e & =(i, j) \in E_{\text {headway }}, i, j \in V_{\text {dep }} \\
x_{j}-x_{i} & \in\left[h a_{s}+r_{e}^{\max }-r_{e}^{\min }, T-h a_{s}+r_{e}^{\max }+r_{e}^{\min }\right]_{T} \\
\forall e & =(i, j) \in E_{\text {headway }}, i, j \in V_{\text {dep }} .
\end{aligned}
$$




$$
\begin{aligned}
& \text { Connection } \\
& x_{j}-x_{i} \in\left[C_{e}^{\min }, C_{e}^{\max }\right]_{T} \\
& \forall e=(i, j) c E_{\text {change }} .
\end{aligned}
$$

Operator Preferences:

$$
x_{i} \geq 0 \quad \forall i \in V \text {. }
$$

The functions minimizing the total event. Constraints of Eq. (2) relate the actual trip time on section. Taking speed variation dynamics into consideration, the trip time in section is flexible between the minimal $r_{e}^{\min }$ and the maximal $r_{e}^{\max }$. As shown in constraints of Eq. (3), train must stop at all stations at which it calls. More precisely, extension of a scheduled stop or additional stops is permitted for operational requirements. Train stoppage time in stations should be within the limits for obvious commercial and operational reasons. Dwell time in stations should be in-between predetermined minimum $d$ well $e_{e}^{\text {min }}$ and maximum $d w e l_{e}^{\max }$ respectively. Minimization of headway between the departure and arrival time of two consecutive trains at one station is described in constraints of Eqs. (4), (5). Constraints of Eq. (6) are applied to describe the connection time between the two trains.

\subsection{Approach based on fixed departure order}

In order to get the optimal cyclic timetable, an approach based on a fixed departure order of original station is proposed and the corresponding model is presented by Eqs. (7)-(13):

$$
\min \sum_{t=1}^{m}\left(a_{t, m}-d_{t, 1}+\sum_{s=1}^{m} k_{t, s} \cdot T+\sum_{s=1}^{m} k_{t, s}^{\prime} \cdot T\right) .
$$

Subject to:

Running time in section

$$
\begin{aligned}
r_{t, s}^{\min } & \leq a_{t, s+1}-d_{t, s}+k_{t, s} T \leq r_{t, s}^{\max }, \\
s & =1,2, \ldots, m-1 ; \quad t=1,2, \ldots, n .
\end{aligned}
$$

Dwell time at station

$$
\begin{aligned}
d w_{t, s}^{\min } & \leq d_{t, s}-a_{t, s}+k_{t, s} T \leq d w_{t, s}^{\max }, \\
s & =1,2, \ldots, m ; \quad t=1,2, \ldots, n .
\end{aligned}
$$

Headway constraint

$$
\begin{aligned}
\left\{\begin{aligned}
d_{t+1, s}-d_{t, s}+k_{t, s}^{\prime} T & \geq h d_{s}, \quad \text { if } \quad r_{t, s}^{\max } \leq r_{t+1, s}^{\min } \\
d_{t+1, s}-d_{t, s}+k_{t, s}^{\prime} T & \geq h a_{s}+r_{t, s}^{\max }-r_{t+1, s}^{\min }
\end{aligned}\right. \\
s=1,2, \ldots, m-1 ; \quad t=1,2, \ldots, n .
\end{aligned}
$$

Overtaking at the intermediate station

$$
\begin{aligned}
a_{t, s}+h a_{s}-a_{t+1, s}-k_{t, s}^{\prime} T & \leq M \cdot\left(1-o_{t, s-1}\right) \\
d_{t+1, s}+h d_{s}-d_{t, s}-k_{t, s}^{\prime} T & \leq M \cdot o_{t, s-1}, \\
s & =2,3, \ldots, m ; \quad t=1,2, \ldots, n-1 .
\end{aligned}
$$

Connection constraint

$$
\begin{aligned}
c_{t, s}^{\min } & \leq d_{t^{\prime}, s+1}-a_{t, s}+k_{t, s}^{\prime} T \leq c_{t, s}^{\max }, \\
s & =1,2, \ldots, m-1 ; \quad t=1,2, \ldots, n .
\end{aligned}
$$

The objective function Eq. (7) strives to minimize the total traveling time of all trains associated with the influence of the parameters of $k_{t, s}$ and $k_{t, s}^{\prime}$. Constraints of Eq. (8) represent the running time of a train in section should be flexible between the minimal $r_{t, s}^{\min }$ and the maximal $r_{t, s}^{\max }$. Constraints of Eq. (9) relate the actual dwell time at station should be no less than the planned minimum dwell time $d w_{t, s}^{\min }$ and no more than the maximum dwell time $d w_{t, s}^{\max }$. The constraints of Eq. (10) describe the maximum and the minimum headway requirements of the departure time between two consecutive trains at one station. It can be seen from Fig. 4 that when the lowspeed train departs after the high-speed train or when the same-speed trains are running subsequently, the headway between two consecutive trains should not be less than the departing headway $h d_{s}$. Besides, when the express train departs after the slow train, the departure headway should be greater than or equal to the sum of the maximum speed difference between the two trains (i.e. the difference between the longest running time of the low-speed train on the segment and the shortest running time of the express train) and the arrival headway $h a_{s}$.

As shown in constraints of Eqs. (11), (12), the faster train can overtake a slower one at the station. So, we use the binary variable $o_{t, s-1}$ to describe the order of the two successive trains occupying the segment. The connection constraints

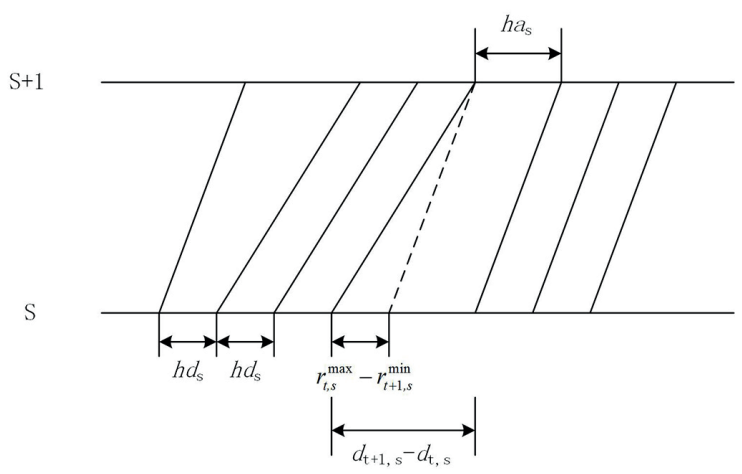

Fig. 4 The departing time interval of tracking trains at the station $s$ 
of Eq. (13) describe the connection time between the two trains $t$ and $t^{\prime}$. If a passenger transfer connection between two trains is desired, then both trains should be present at the connecting station at about the same time. So the connection time between two trains should be flexible between the minimal $c_{t, s}^{\min }$ and the maximal $c_{t, s}^{\max }$.

\section{Case study}

In order to evaluate the performance of the cyclic timetable, we apply the proposed mathematical model on the Guangzhou-Zhuhai HSR shown in Fig. 5. GuangzhouZhuhai HSR line is composed of a main line and a branch line. A total of 23 stations along the line and 18 stations on the main line while Cuiheng, Jianghai and Lile railway station are not currently open.

\subsection{The cyclic train timetabling}

Taking into account the entire running time of a train is more than 1 hour, and according to the working time standard of 20 minutes at the turnaround stations, we set the cycle length $T$ equal to 120 minutes, which can reduce drawing of the cross-table train lines. The headway is set to be $3 \mathrm{~min}$ to

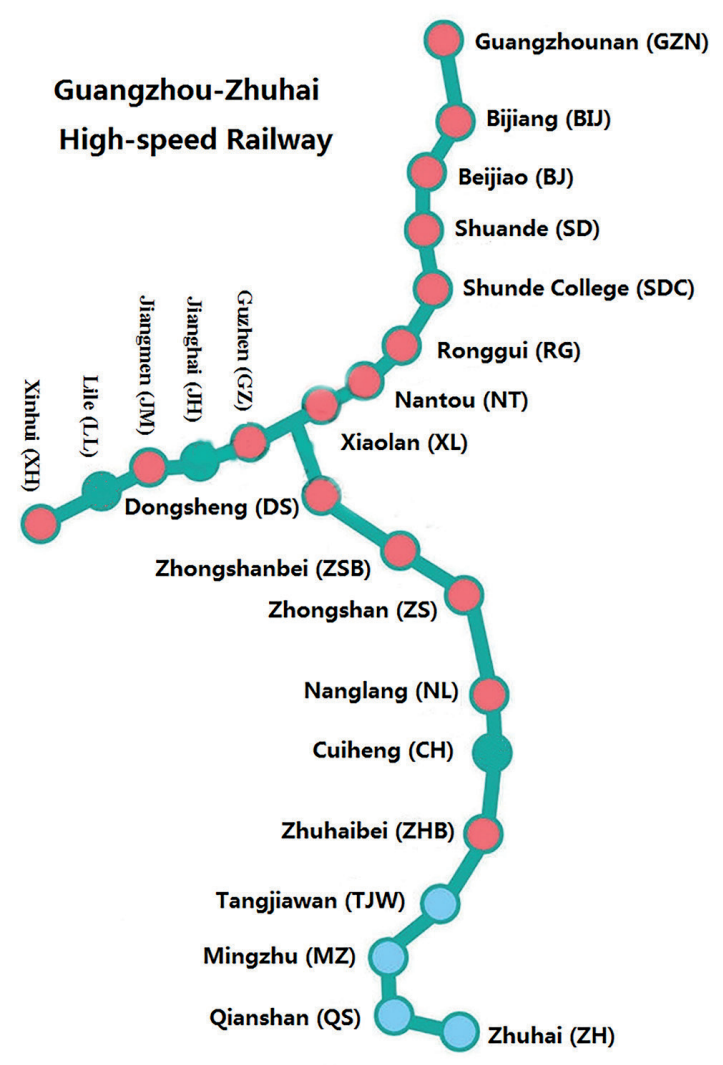

Fig. 5 The topology of the Guangzhou-Zhuhai HSR line simplify the problem. Cyclic train timetable is adopted in this article, taking 6:00 to $8: 00$ as a peak unit time while 12 trains are operated in the timeslot. The train stop plan of the Guangzhou-Zhuhai HSR line is shown as Fig. 6.

We can get the optimal solution is 786 minutes, that is, the shortest travel time of all trains in a cycle time is $13 \mathrm{~h}$ $6 \mathrm{~min}$. Scheduling the departure time and arrival time of every train at each station, the train arrangement during one cycle is shown in Table 3, and the unit cycle diagram is drawn as Fig. 7.

It is shown from Table 3 that 12 trains can be drawn in a peak cycle time, including 9 trains from Guangzhounan to Zhuhai, which include one nonstop train and five express train that stops at major stations, and three trains with staggered stop between the large stations and the small stations. Besides, there are also three trains that travel from Guangzhou South to Xinhui which is demonstrated in Fig. 7, showing no cross interference between the situation at the end of the cycle period and the situation at the start of the one the full-day timetable can be obtained by copying the cyclic timetable for all the relevant hours of the day.

The whole day is divided into 9 parts with a unit of two hours, and the number of trains in per unit time is arranged as shown in Table 4. Among them, 6:00 8:00, 12:00 14:00 and 18:00 20:00 are peak hours of the whole day, during which trains are operated according to the maximum number of 12 . Some trains can be removed during low-traffic hours appropriately.

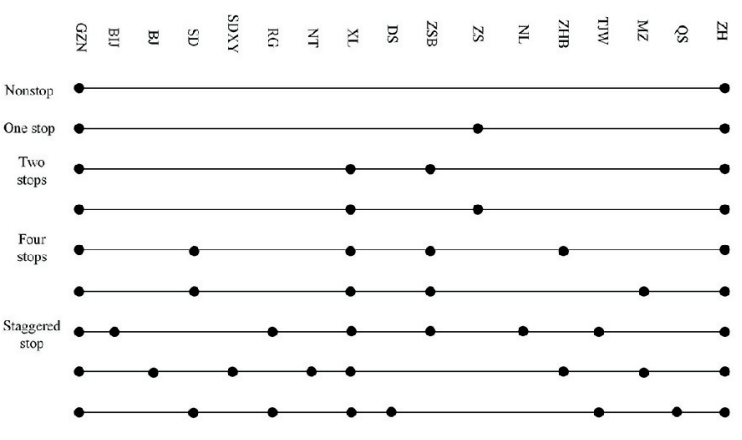

(a) Guangzhounnan-Zhuhai

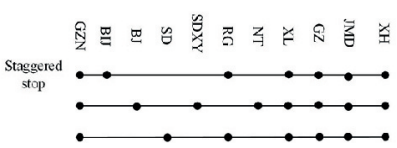

(b) Guangzhounnan-Xinhui

Fig. 6 The train stop plan of the Guangzhou-Zhuhai HSR line 
Table 3 The train schedule of a cycle time for the Guangzhou-Zhuhai HSR

\begin{tabular}{|c|c|c|c|c|c|c|c|c|c|c|c|c|c|}
\hline \multirow{2}{*}{ Number } & \multirow{2}{*}{ STATION } & \multicolumn{12}{|c|}{ TRAIN } \\
\hline & & C701 & C703 & C705 & C707 & C709 & C711 & C713 & C715 & C717 & C601 & C603 & C605 \\
\hline 01 & GZN & $6: 30$ & $6: 35$ & $6: 40$ & $6: 45$ & $6: 50$ & $7: 15$ & $7: 20$ & $7: 28$ & $7: 47$ & $6: 55$ & $7: 34$ & 8:00 \\
\hline 02 & BIJ & $\begin{array}{c}\ldots \\
6: 34\end{array}$ & $\begin{array}{c}\ldots \\
6: 39\end{array}$ & $\begin{array}{c}\ldots \\
6: 44\end{array}$ & $\begin{array}{c}\ldots \\
6: 49\end{array}$ & $\begin{array}{c}\ldots \\
6: 54\end{array}$ & $\begin{array}{c}\ldots \\
7: 19\end{array}$ & $\begin{array}{c}\ldots \\
7: 24\end{array}$ & $\begin{array}{l}7: 33 \\
7: 35\end{array}$ & $\begin{array}{c}\ldots \\
7: 51\end{array}$ & $\begin{array}{c}\ldots \\
6: 59\end{array}$ & $\begin{array}{l}7: 39 \\
7: 41\end{array}$ & $\begin{array}{c}\ldots \\
8: 04\end{array}$ \\
\hline 03 & BJ & $\begin{array}{c}\ldots \\
6: 36\end{array}$ & $\begin{array}{c}\ldots \\
6: 41\end{array}$ & $\begin{array}{c}\ldots \\
6: 46\end{array}$ & $\begin{array}{c}\ldots \\
6: 51\end{array}$ & $\begin{array}{l}6: 57 \\
6: 59\end{array}$ & $\begin{array}{c}\ldots \\
7: 21\end{array}$ & $\begin{array}{c}\ldots \\
7: 26\end{array}$ & $\begin{array}{c}\ldots \\
7: 39\end{array}$ & $\begin{array}{c}\ldots \\
7: 53\end{array}$ & $\begin{array}{l}\text { 7:02 } \\
7: 04\end{array}$ & $\begin{array}{c}\ldots \\
7: 45\end{array}$ & $\begin{array}{c}\ldots \\
\text { 8:06 }\end{array}$ \\
\hline 04 & $\mathrm{SD}$ & $\begin{array}{c}\ldots \\
6: 37\end{array}$ & $\begin{array}{c}\ldots \\
6: 42\end{array}$ & $\begin{array}{c}\ldots \\
6: 47\end{array}$ & $\begin{array}{l}6: 53 \\
6: 55\end{array}$ & $\begin{array}{c}\ldots \\
7: 02\end{array}$ & $\begin{array}{c}\ldots \\
7: 22\end{array}$ & $\begin{array}{l}7: 28 \\
7: 30\end{array}$ & $\begin{array}{c}\ldots \\
7: 40\end{array}$ & $\begin{array}{l}7: 55 \\
7: 57\end{array}$ & $\begin{array}{c}\ldots \\
7: 07\end{array}$ & $\begin{array}{c}\ldots \\
7: 46\end{array}$ & $\begin{array}{l}8: 08 \\
8: 10\end{array}$ \\
\hline 05 & SDC & $\begin{array}{c}\ldots \\
6: 40\end{array}$ & $\begin{array}{c}\ldots \\
6: 45\end{array}$ & $\begin{array}{c}\ldots \\
6: 50\end{array}$ & $\begin{array}{c}\ldots \\
7: 00\end{array}$ & $\begin{array}{l}7: 06 \\
7: 08\end{array}$ & $\begin{array}{c}\ldots \\
7: 25\end{array}$ & $\begin{array}{c}\ldots \\
7: 35\end{array}$ & $\begin{array}{c}\ldots \\
7: 43\end{array}$ & $\begin{array}{c}\ldots \\
8: 02\end{array}$ & $\begin{array}{l}\text { 7:11 } \\
7: 13\end{array}$ & $\begin{array}{c}\ldots \\
7: 49\end{array}$ & $\begin{array}{c}\ldots \\
8: 15\end{array}$ \\
\hline 06 & RG & $\begin{array}{c}\ldots \\
6: 43\end{array}$ & $\begin{array}{c}\ldots \\
6: 48\end{array}$ & $\begin{array}{c}\ldots \\
6: 53\end{array}$ & $\begin{array}{c}\ldots \\
7: 03\end{array}$ & $\begin{array}{c}\ldots \\
7: 13\end{array}$ & $\begin{array}{c}\ldots \\
7: 28\end{array}$ & $\begin{array}{c}\ldots \\
7: 38\end{array}$ & $\begin{array}{l}7: 47 \\
7: 49\end{array}$ & $\begin{array}{l}8: 06 \\
\text { 8:13 }\end{array}$ & $\begin{array}{c}\ldots \\
7: 18\end{array}$ & $\begin{array}{l}7: 53 \\
7: 55\end{array}$ & $\begin{array}{l}8: 19 \\
8: 21\end{array}$ \\
\hline 07 & NT & $\begin{array}{c}\ldots \\
6: 45\end{array}$ & $\begin{array}{c}\ldots \\
6: 50\end{array}$ & $\begin{array}{c}\ldots \\
6: 55\end{array}$ & $\begin{array}{c}\ldots \\
7: 05\end{array}$ & $\begin{array}{l}\text { 7:16 } \\
7: 18\end{array}$ & $\begin{array}{c}\ldots \\
7: 30\end{array}$ & $\begin{array}{c}\ldots \\
7: 40\end{array}$ & $\begin{array}{c}\ldots \\
7: 53\end{array}$ & $\begin{array}{c}\ldots \\
8: 17\end{array}$ & $\begin{array}{l}7: 21 \\
7: 23\end{array}$ & $\begin{array}{c}\ldots \\
7: 59\end{array}$ & $\begin{array}{c}\ldots \\
8: 25\end{array}$ \\
\hline 08 & XL & $\begin{array}{c}\ldots \\
6: 47\end{array}$ & $\begin{array}{c}\ldots \\
6: 52\end{array}$ & $\begin{array}{l}6: 58 \\
7: 00\end{array}$ & $\begin{array}{l}7: 08 \\
7: 11\end{array}$ & $\begin{array}{l}7: 23 \\
7: 25\end{array}$ & $\begin{array}{l}7: 33 \\
7: 35\end{array}$ & $\begin{array}{l}7: 43 \\
7: 45\end{array}$ & $\begin{array}{l}7: 56 \\
7: 59\end{array}$ & $\begin{array}{l}8: 20 \\
8: 23\end{array}$ & $\begin{array}{l}7: 28 \\
7: 31\end{array}$ & $\begin{array}{l}8: 02 \\
8: 04\end{array}$ & $\begin{array}{l}8: 28 \\
8: 35\end{array}$ \\
\hline 09 & DS & $\begin{array}{c}\ldots \\
6: 49\end{array}$ & $\begin{array}{c}\ldots \\
6: 54\end{array}$ & $\begin{array}{c}\ldots \\
7: 04\end{array}$ & $\begin{array}{c}\ldots \\
7: 15\end{array}$ & $\begin{array}{c}\ldots \\
7: 29\end{array}$ & $\begin{array}{c}\ldots \\
7: 39\end{array}$ & $\begin{array}{c}\ldots \\
7: 49\end{array}$ & $\begin{array}{c}\ldots \\
8: 03\end{array}$ & $\begin{array}{l}8: 28 \\
8: 30\end{array}$ & & & \\
\hline 10 & ZSB & $\begin{array}{c}\ldots \\
6: 53\end{array}$ & $\begin{array}{c}\ldots \\
6: 58\end{array}$ & $\begin{array}{l}7: 09 \\
7: 11\end{array}$ & $\begin{array}{l}7: 20 \\
7: 22\end{array}$ & $\begin{array}{c}\ldots \\
7: 33\end{array}$ & $\begin{array}{c}\ldots \\
7: 43\end{array}$ & $\begin{array}{l}7: 54 \\
7: 57\end{array}$ & $\begin{array}{l}8: 08 \\
8: 11\end{array}$ & $\begin{array}{c}\ldots \\
8: 36\end{array}$ & & & \\
\hline 11 & ZS & $\begin{array}{c}\ldots \\
6: 55\end{array}$ & $\begin{array}{l}7: 01 \\
7: 04\end{array}$ & $\begin{array}{c}\ldots \\
7: 15\end{array}$ & $\begin{array}{c}\ldots \\
7: 26\end{array}$ & $\begin{array}{c}\ldots \\
7: 35\end{array}$ & $\begin{array}{l}7: 46 \\
7: 48\end{array}$ & $\begin{array}{c}\ldots \\
\text { 8:01 }\end{array}$ & $\begin{array}{c}\ldots \\
8: 15\end{array}$ & $\begin{array}{c}\ldots \\
8: 38\end{array}$ & & & \\
\hline 12 & NL & $\begin{array}{c}\ldots \\
6: 59\end{array}$ & $\begin{array}{c}\ldots \\
7: 10\end{array}$ & $\begin{array}{c}\ldots \\
7: 19\end{array}$ & $\begin{array}{c}\ldots \\
7: 30\end{array}$ & $\begin{array}{c}\ldots \\
7: 39\end{array}$ & $\begin{array}{c}\ldots \\
7: 54\end{array}$ & $\begin{array}{c}\ldots \\
8: 05\end{array}$ & $\begin{array}{l}8: 20 \\
8: 22\end{array}$ & $\begin{array}{c}\ldots \\
8: 42\end{array}$ & & & \\
\hline 13 & ZHB & $\begin{array}{c}\ldots \\
7: 02\end{array}$ & $\begin{array}{c}\ldots \\
7: 13\end{array}$ & $\begin{array}{c}\ldots \\
7: 22\end{array}$ & $\begin{array}{l}7: 34 \\
7: 36\end{array}$ & $\begin{array}{l}7: 43 \\
7: 45\end{array}$ & $\begin{array}{c}\ldots \\
7: 57\end{array}$ & $\begin{array}{c}\ldots \\
8: 08\end{array}$ & $\begin{array}{c}\ldots \\
8: 27\end{array}$ & $\begin{array}{c}\ldots \\
8: 45\end{array}$ & & & \\
\hline 14 & TJW & $\begin{array}{c}\ldots \\
7: 03\end{array}$ & $\begin{array}{c}\ldots \\
7: 14\end{array}$ & $\begin{array}{c}\ldots \\
7: 23\end{array}$ & $\begin{array}{c}\ldots \\
7: 39\end{array}$ & $\begin{array}{c}\ldots \\
7: 48\end{array}$ & $\begin{array}{c}\ldots \\
7: 58\end{array}$ & $\begin{array}{c}\ldots \\
8: 09\end{array}$ & $\begin{array}{l}8: 29 \\
8: 31\end{array}$ & $\begin{array}{l}8: 47 \\
8: 49\end{array}$ & & & \\
\hline 15 & $\mathrm{MZ}$ & $\begin{array}{c}\ldots \\
7: 08\end{array}$ & $\begin{array}{c}\ldots \\
7: 19\end{array}$ & $\begin{array}{c}\ldots \\
7: 28\end{array}$ & $\begin{array}{c}\ldots \\
7: 44\end{array}$ & $\begin{array}{l}7: 54 \\
7: 56\end{array}$ & $\begin{array}{c}\ldots \\
8: 03\end{array}$ & $\begin{array}{l}8: 15 \\
8: 17\end{array}$ & $\begin{array}{c}\ldots \\
8: 38\end{array}$ & $\begin{array}{c}\ldots \\
8: 56\end{array}$ & & & \\
\hline 16 & QS & $\begin{array}{c}\ldots \\
7: 12\end{array}$ & $\begin{array}{c}\ldots \\
7: 23\end{array}$ & $\begin{array}{c}\ldots \\
7: 32\end{array}$ & $\begin{array}{c}\ldots \\
7: 48\end{array}$ & $\begin{array}{c}\ldots \\
8: 02\end{array}$ & $\begin{array}{c}\ldots \\
8: 07\end{array}$ & $\begin{array}{c}\ldots \\
8: 23\end{array}$ & $\begin{array}{c}\ldots \\
8: 42\end{array}$ & $\begin{array}{l}\text { 9:01 } \\
\text { 9:03 }\end{array}$ & & & \\
\hline 17 & $\mathrm{ZH}$ & $7: 20$ & $7: 30$ & $7: 39$ & $7: 55$ & 8:09 & $8: 16$ & $8: 30$ & $8: 49$ & $9: 12$ & & & \\
\hline 18 & $\mathrm{GZ}$ & & & & & & & & & & $\begin{array}{l}7: 38 \\
7: 40\end{array}$ & $\begin{array}{l}8: 11 \\
8: 13\end{array}$ & $\begin{array}{l}8: 42 \\
8: 44\end{array}$ \\
\hline 19 & JMD & & & & & & & & & & $\begin{array}{l}7: 47 \\
7: 49\end{array}$ & $\begin{array}{l}8: 20 \\
8: 22\end{array}$ & $\begin{array}{l}8: 51 \\
8: 53\end{array}$ \\
\hline 20 & $\mathrm{XH}$ & & & & & & & & & & $7: 56$ & $8: 29$ & 9:00 \\
\hline
\end{tabular}

Table 4 The number of trains in each cycle time

\begin{tabular}{|c|c|c|c|c|c|c|c|c|c|c|}
\hline Unit Time & & $\begin{array}{l}6: 00- \\
8: 00\end{array}$ & $\begin{array}{l}8: 00- \\
10: 00\end{array}$ & $\begin{array}{c}10: 00- \\
12: 00\end{array}$ & $\begin{array}{c}12: 00- \\
14: 00\end{array}$ & $\begin{array}{c}14: 00- \\
16: 00\end{array}$ & $\begin{array}{c}16: 00- \\
18: 00\end{array}$ & $\begin{array}{l}18: 00- \\
20: 00\end{array}$ & $\begin{array}{c}20: 00- \\
22: 00\end{array}$ & $\begin{array}{r}22: 00 \\
0: 00\end{array}$ \\
\hline Main & Optimization scheme & 9 & 8 & 6 & 9 & 6 & 8 & 9 & 8 & 4 \\
\hline \multirow{2}{*}{ Branch } & Optimization scheme & 3 & 3 & 2 & 3 & 2 & 3 & 3 & 3 & 1 \\
\hline & Current scheme & 3 & 2 & 2 & 3 & 2 & 2 & 3 & 2 & 0 \\
\hline
\end{tabular}

\subsection{Results analysis}

\subsubsection{Basic indexes}

When we compare the related indexes of the current operation scheme and the optimization plan as shown in Table 5, we can see that lager increase in total number of trains and higher service frequency of railway stations can be achieved: about 24 trains and 7 nonstop trains are risen with the optimization schedule, in addition, the average headway time reduces 3 minutes. So the establishment of optimization model is efficient. 


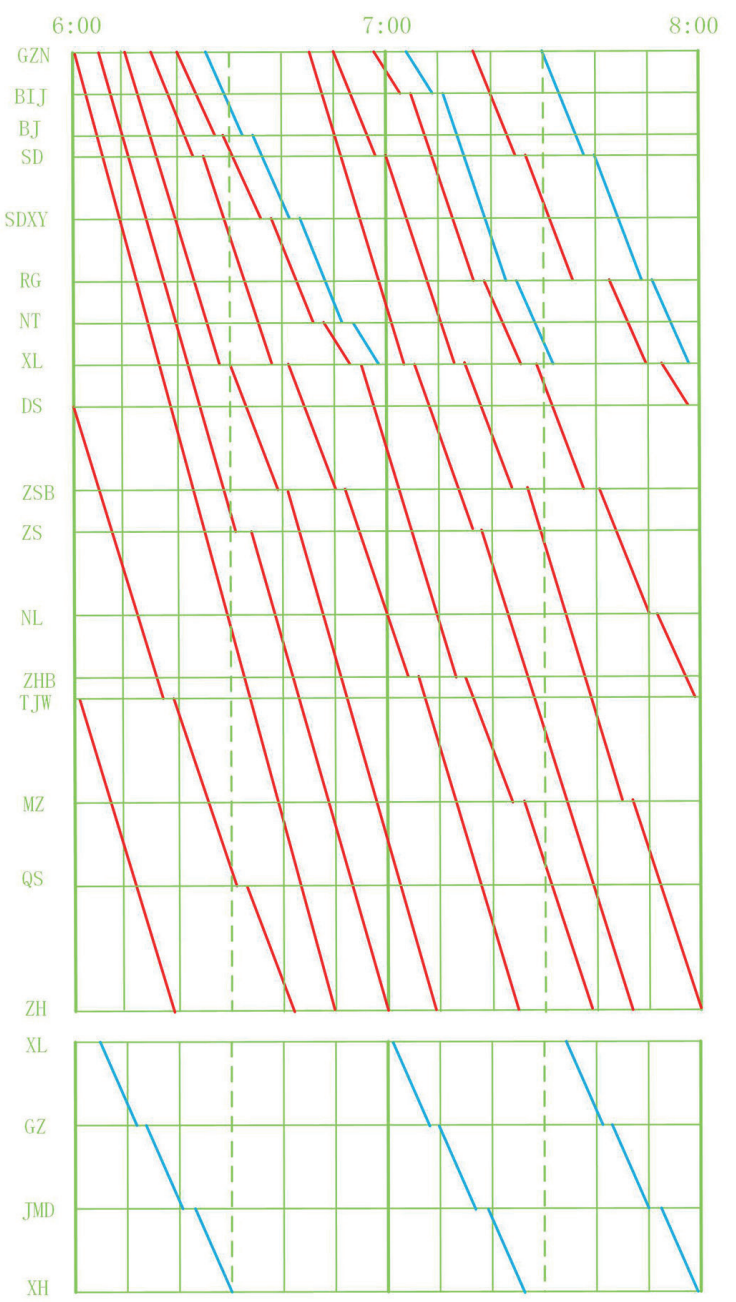

Fig. 7 The unit cycle operation diagram of the Guangzhou-Zhuhai HSR line

Table 5 Comparison of optimization results

\begin{tabular}{lccc}
\hline Indexs of timetable & $\begin{array}{c}\text { Current } \\
\text { schedule }\end{array}$ & $\begin{array}{c}\text { Optimization } \\
\text { scheme }\end{array}$ &,+- \\
\hline $\begin{array}{l}\text { Total number of trains } \\
\text { Number of the nonstop } \\
\text { trains }\end{array}$ & 66 & 90 & +24 \\
$\begin{array}{l}\text { Average times of } \\
\text { stopping }\end{array}$ & 3.5 & 9 & +7 \\
Average headway time & 13 & 10 & +0.2 \\
\hline
\end{tabular}

Comparing the optimized unit cycle operation diagram and the current train timetable of Guangzhou-Zhuhai HSR line from 6:00 to 8:00, we can see that by using the cyclic train timetable, the train operation density of the Guangzhou-Zhuhai HSR line is increasing, and the aggregated number of the trains is growing, which is fairly good to meet the transportation demand.

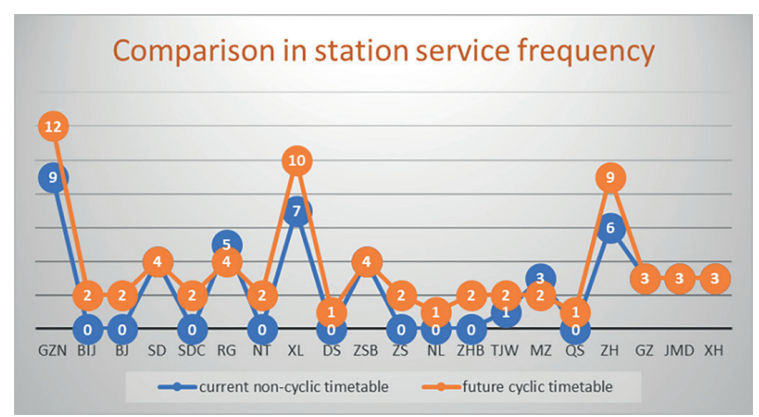

Fig. 8 Comparison of current non-cyclic timetable and future cyclic timetable in station service frequency

\subsubsection{Service frequency of stations}

The service frequency of each station in future cyclic timetable is counted and compared with the current non-cyclic ones, as shown in Fig. 8.

It can be clearly seen from the Fig. 8 that in the future cyclic timetable almost all of the stations (except Ronggui and Mingzhu railway station) has higher train service frequency than it in the current non-cyclic timetable, which implies the cyclic timetable could provide passengers more train options at these stations.

\section{Conclusion}

In this paper we established an optimization model of cyclic train timetable, in which the minimization of the total train travelling time is the objective. The cyclic timetabling problem was formulated based on the event-activity graph with considering many general constraints, such as running time, dwell time, headway, and connection constraints. The real world overtaking rule that concerning a train with higher priority would not be overtaken by a slower one was also taken into account in this paper. In order to get an optimal cyclic timetable within reasonable time, an approach based on fixed departure order was proposed. We presented examples from Guangzhou-Zhuhai HSR railway in China to show the effective of the introduced model and approach.

Future extension on this problem might be as follows. Firstly, the multi-objectives model can be development, for example, besides the minimum travel time for passengers, the cost or profile for railway company should also be taken into account. Secondly, various predefined order would lead to different cyclic timetable which should be tested exactly. Thirdly, the integration of several planning steps should be considered in ongoing and future work, such as a combination of passenger flow forecasting and timetabling problem, or a combination of train line planning and timetabling problem. 


\section{Acknowledgement}

The project presented in this article is supported by Fundamental Research Funds for the Central Universities (No. 2018JBM027), the 111 Project of China (No. B18004),

\section{References}

Castillo, E., Gallego, I., Ureña, J. M., Coronado, J. M. (2011) "Timetabling optimization of a mixed double- and single-tracked railway network", Applied Mathematical Modelling, 35(2), pp. 859-878. https://doi.org/10.1016/j.apm.2010.07.041

Central Japan Railway Company (2013) "Central Japan Railway Company Annual Report 2013", Central Japan Railway Company. [online] Available at: http://www.doc88.com/p-9415295781193. html [Accessed: 14 October 2017]

Heydar, M., Petering, M. E. H., Bergmann, D. R. (2013) "Mixed integer programming for minimizing the period of a cyclic railway timetable for a single track with two train types", Computers \& Industrial Engineering, 66(1), pp. 171-185.

https://doi.org/10.1016/j.cie.2013.06.003

Kroon, L. G., Peeters, L. W. P., Wagenaar, J. C., Zuidwijk, R. A. (2013) "Flexible Connections in PESP Models for Cyclic Passenger Railway Timetabling", Transportation Science, 48(1), pp. 136-154. https://doi.org/10.1287/trsc.1120.0453

Mackenzie, S. (2000) "Train Timetabling on Complex Networks", In: Conference on Railway Engineering 2000 (CORE 2000), Adelaide, Australia, pp. 76-81.

Oliveira, E., Smith, B. M. (2001) "A hybrid constraint-based method for single-track railway scheduling problem", School of Computer Studies, University of Leeds, United Kingdom, Technical Report: LU-SCS-RR--2001/04. [online] Available at: http://hdl.handle. net/10068/624810 [Accessed: 12 January 2018]

Mu, S., Dessouky, M. (2011) "Scheduling freight trains traveling on complex networks", Transportation Research Part B: Methodological, 45(7), pp. 1103-1123.

https://doi.org/10.1016/j.trb.2011.05.021

Peeters, L. W. P. (2003) "Cyclic Railway Timetable Optimization", ERIM Ph.D. Series Research in Management, Erasmus University Rotterdam, Rotterdam, The Netherlands. [online] Available at: http://hdl.handle.net/1765/429 [Accessed: 10 October 2017]

Robenek, T., Azadeh, S. S., Maknoon, Y., Bierlaire, M. (2017) "Hybrid cyclicity: Combining the benefits of cyclic and non-cyclic timetables", Transportation Research Part C: Emerging Technologies, 75 , pp. $228-253$.

https://doi.org/10.1016/j.trc.2016.12.015 the National Key Research and Development Program of China (No. 2018YFB1201402), and the National Natural Science Foundation of China (Grant Nos. U1434207, U1734204).

Schachtebeck, M. (2010) "Delay Management in Public Transportation: Capacities, Robustness, and Integration", Ph.D. Thesis, GeorgAugust-Universität Göttingen, Göttingen, Germany. [online] Available at: http://hdl.handle.net/11858/00-1735-0000-0006B3CE-4 [Accessed: 28 December 2017]

Schöbel, A. (2001) "A Model for the Delay Management Problem based on Mixed-Integer-Programming", Electronic Notes in Theoretical Computer Science, 50(1), pp. 1-10. https://doi.org/10.1016/S1571-0661(04)00160-4

Schöbel, A. (2007) "Integer Programming Approaches for Solving the Delay Management Problem", In: Geraets, F., Kroon, L., Schoebel, A., Wagner, D., Zaroliagis, C. D. (eds.) Algorithmic Methods for Railway Optimization, Lecture Notes in Computer Science, 3rd ed., Springer, Berlin, Heidelberg, Germany, pp. 145-170. https://doi.org/10.1007/978-3-540-74247-0_7

Serafini, P., Ukovich, W. (1989) "A Mathematical Model for Periodic Scheduling Problems", SIAM Journal on Discrete Mathematics, 2(4), pp. 550-581. https://doi.org/10.1137/0402049

Su, S., Li, X., Tang, T., Gao, Z. (2013) "A Subway Train Timetable Optimization Approach Based on Energy-Efficient Operation Strategy", IEEE Transactions on Intelligent Transportation Systems, 14(2), pp. 883-893. https://doi.org/10.1109/TITS.2013.2244885

Törnquist, J., Persson, J. A. (2007) "N-Tracked Railway Traffic Re-Scheduling During Disturbances", Transportation Research Part B: Methodological, 41(3), pp. 342-362. https://doi.org/10.1016/j.trb.2006.06.001

Xie, M., Nie, L. (2009) "Model of Cyclic Train Timetable", Journal of the China Railway Society, 31(4), pp. 7-13. https://doi.org/10.3969/j.issn.1001-8360.2009.04.012

Zimmermann, U. T., Lindner, T. (2000) "Train Schedule Optimization in Public Rail Transport", In: Jäger, W., Krebs, H. J. (eds.) Mathematics - Key Technology for the Future, 2nd ed., Springer, Berlin, Heidelberg, Germany, pp. 703-716. https://doi.org/10.1007/978-3-642-55753-8_53 